\title{
Incorporation of a gravity wave momentum deposition parameterization into the Venus Thermosphere General Circulation Model (VTGCM)
}

\author{
A. M. Zalucha, ${ }^{1}$ A. S. Brecht, ${ }^{2}$ S. Rafkin, ${ }^{3}$ S. W. Bougher, ${ }^{4}$ and M. J. Alexander ${ }^{5}$ \\ Received 24 June 2012; revised 12 November 2012; accepted 12 December 2012; published 31 January 2013.
}

[1] The gravity wave-drag parameterization of Alexander and Dunkerton (1999) was implemented into a Venus Thermosphere General Circulation Model (VTGCM) to investigate breaking gravity waves as a source of momentum deposition in Venus' thermosphere. Previously, deceleration of zonal jets on the morning and evening terminators in models was accomplished via Rayleigh friction, a linear drag law that is not directly linked to any physical mechanism. The Alexander and Dunkerton (1999) parameterization deposits all of the momentum of a breaking wave at the breaking altitude and features a spectrum of wave phase speeds whose amplitudes are distributed as a Gaussian about a center phase speed. We did not find a combination of wave parameters (namely, center phase speed, amplitude at center phase speed, and distribution width) to produce sufficient drag in the jet cores that would bring VTGCM density and nightglow emissions into agreement with Venus Express observations. The zonal wind shear from 100 to $120 \mathrm{~km}$ altitude is very strong. Gravity waves launched below $100 \mathrm{~km}$ either break in the strong shear zones below $115 \mathrm{~km}$ or are reflected and do not propagate into the jet core regions where drag is needed. The results we present demonstrate that parameterizations developed for the middle atmosphere do not work in the thermosphere and that appropriate damping mechanisms other than nonlinear breaking/saturation dominate and should be accounted for at these heights.

Citation: Zalucha, A. M., A. S. Brecht, S. Rafkin, S. W. Bougher, and M. J. Alexander (2013), Incorporation of a gravity wave momentum deposition parameterization into the Venus Thermosphere General Circulation Model (VTGCM), J. Geophys. Res. Planets, 118, 147-160, doi:10.1029/2012JE004168.

\section{Introduction}

[2] Early work with terrestrial global climate models required an ad hoc forcing near the model top to prevent reflection of numerically resolved waves off the model top and to match observations of winter jets in the middle atmosphere [see Kim et al., 2003, for a review]. Specifically, this parameterization was Rayleigh friction [e.g., Leovy, 1964], a momentum sink that was linearly dependent on velocity and increased in magnitude with height. More elaborate schemes varied this forcing in time and space until the desired result was achieved. A "sponge" layer existed in the uppermost model levels where Rayleigh friction acted,

\footnotetext{
${ }^{1}$ SETI Institute, Mountain View, California, USA.

${ }^{2}$ NASA Ames Research Center, Moffett Field, California, 94035, USA.

${ }^{3}$ Department of Space Studies, Southwest Research Institute, Boulder, Colorado, USA

${ }^{4}$ Department of Atmospheric, Oceanic, and Space Sciences, University of Michigan, Ann Arbor, Michigan, USA.

${ }^{5}$ NorthWest Research Associates - CoRA, 3380 Mitchell Lane, Boulder, Colorado, USA.

Corresponding author: A. M. Zalucha, A. M. Zalucha Consulting Boulder, CO, USA. (azalucha@seti.org)

(C) 2012. American Geophysical Union. All Rights Reserved. 2169-9097/13/2012JE004168
}

but it could not reproduce the observed reversals of zonal wind direction in the mesosphere [Shepherd et al., 1996].

[3] Eventually, it was discovered that the breaking of subgrid scale gravity waves (or buoyancy or internal waves) was the mechanism responsible for momentum drag, and a parameterization of these effects was proposed by Lindzen [1981]. While the theory behind linear, small-amplitude, idealized gravity waves is well understood, these waves present a problem for global climate models because their typical wavelength is smaller than the grid spacing. Additionally, sources of gravity waves are numerous and diverse, including thunderstorms, flow over topography, and baroclinic instabilities. Gravity waves are emitted from these sources in all directions. Vertically propagating gravity waves increase in amplitude as atmospheric density decreases, until they become highly nonlinear and break, depositing their momentum and accelerating or decelerating the background flow.

[4] Several methods have been developed to determine the amount of momentum deposition from gravity waves based on large-scale model state variables. The first was originally proposed by Lindzen [1981], which assumes that waves have a single phase speed and horizontal wave number. When the waves reach the level of linear instability, they saturate and continue propagating upward by a finite distance 
by dissipating just enough momentum for the wave to remain stable. Further improvements were described by Holton [1982], Lindzen [1985], Fritts [1984], and Dunkerton [1989].

[5] Another method, put forth by Lindzen and Holton [1968], prescribes the waves to deposit all of their momentum at the critical level (where the phase speed equals the background wind speed in the direction of propagation). This scheme allows for a spectrum of wave speeds where each wave will in general break at a different level. Alexander and Dunkerton [1999] is a hybrid of the Lindzen and Holton [1968] and Lindzen [1981] schemes, where the waves have a spectrum of wave speeds that deposit all their momentum at one level but have a breaking criterion defined by Lindzen [1981].

[6] The Alexander and Dunkerton [1999] scheme does not contain wave saturation effects, which would distribute momentum over a wider altitude range. This scheme is in contrast to the Venus gravity wave-drag scheme of Zhang et al. [1996], which distributes the energy of the waves throughout the atmosphere based on gravity wavedrag saturation theory and empirical observations of Earth from Fritts and $\mathrm{Lu}$ [1993]. Recent direct numerical simulations by Fritts et al. [2009] investigate two wave breaking cases at different amplitudes (for the case of no shear), one just above the stability limit and one below. These simulations resolve the primary wave that breaks, well into the turbulence spectrum. They show that the remaining momentum flux after breaking is less than $8 \%$ of the original. In the shear case, the amount remaining would generally be even less.

[7] Just like Earth, Venus's atmosphere also contains gravity waves and planetary-scale waves. Their existence is easily confirmed using photographs of Venus' clouds [e.g., Belton et al., 1976b; Belton et al., 1976c; Belton et al., 1976a; Rossow et al., 1980; Peralta et al., 2008]. Some of the wave structures are seen as bands at ultraviolet wavelengths; these bands are traveling waves because the bands do not align with any circle of latitude, and the bands travel at a different velocity than the background velocity [Schubert, 1983]. The most noted wave feature is the dark horizontal "Y" [e.g., Belton et al., 1976b; Belton et al., 1976c; Belton et al., 1976a; Rossow et al., 1980; Schubert, 1983].

[8] Gravity waves are also a suggested source for the deceleration of Venus' zonal flow. There have been very limited observations; however, evidence of gravity waves exists in Pioneer Venus (PV) probe and Orbiter Atmospheric Drag data [Seiff, 1991] and PV Orbiter Neutral Mass Spectrometer (ONMS) data [Kasprzak et al., 1988, 1993]. Kasprzak et al. [1988] examined the PV ONMS data and found wave structures with a wavelength range from 100 to $600 \mathrm{~km}$, and the amplitudes varied depending on the molecular weight of the species $\left(\mathrm{He}, \mathrm{N}, \mathrm{O}, \mathrm{N}_{2}\right.$, and $\mathrm{CO}_{2}$ ). Other observations by PV probes and bus were minimal and only able to detect wave perturbations but not characterize them [Seiff et al., 1980; Seiff, 1991; von Zahn et al., 1980]. Moreover, vertical wavelengths above the cloud tops $(\sim 20 \mathrm{~km})$ and below $(\sim 5-10 \mathrm{~km})$ were deduced from temperature observations [Taylor et al., 1980]. Clouds have been visually observed with a wide horizontal scale from $100 \mathrm{~km}$ to hundreds of kilometers with periods of 4 to 6 days [Schubert, 1983]. Additional details on waves from PV observations are discussed in Schubert [1983].
[9] More recently, the Venus Express (VEx) mission has been augmenting knowledge of gravity waves in Venus' atmosphere by identifying gravity waves in regular cloud patterns [Markiewicz et al., 2007; Peralta et al., 2008]. Waves were also observed in vertical variations of infrared temperature soundings, radio occultation temperatures, upper atmosphere number densities, and other atmospheric quantities [e.g., Schubert, 1983; Covey and Schubert, 1981a, 1981b, 1982; Kasprzak et al., 1988; Bougher et al., 1997]. Furthermore, thermal tides have been observed in thermal structure data and in the atmospheric circulation [Schofield and Taylor, 1983; Limaye, 1990].

[10] The Visible and Infrared Thermal Imaging Spectrometer (VIRTIS) instrument on VEx has detected perturbations in $\mathrm{CO}_{2}$ non-local thermodynamic equilibrium emissions [ Garcia et al., 2009]. From these observations, they are able to obtain wave structures with horizontal wavelengths ranging from 90 to $400 \mathrm{~km}$. Additionally, derived horizontal phase velocities (magnitude and direction) are consistent between orbits and are on average of $70 \mathrm{~m} \mathrm{~s}^{-1}$ westward and $30 \mathrm{~m} \mathrm{~s}^{-1}$ northward [Garcia et al., 2009]. Garcia et al. [2009] claim these observed waves are generated from the polar vortex (note that in our study we do not consider wave ducting from distant locations). Moreover, VIRTIS and Venus Monitoring Camera observed visible trains of oscillating cloud brightness in the UV for an upper cloud layer $(\sim 66 \mathrm{~km})$ on the dayside and thermal radiation for the lower cloud layer on the nightside [Peralta et al., 2008]. Wavelengths and phase speeds are also derived from these observations. Peralta et al. [2008] observed wavelengths of $60-150 \mathrm{~km}$, which propagate westward with phase velocities similar to the zonal flow and are confined to horizontal wave packets of 400 to $1800 \mathrm{~km}$ in length. They find no correlation between the waves and surface topography, latitude, local time, or wind structure. The perturbations in the observations help provide information on gravity waves in Venus' atmosphere, which are very important in constraining gravity wave formulations within 3-D models.

[11] Wave drag was first modeled as part of a Venus thermosphere general circulation model (VTGCM) by Bougher et al. [1988], who found good agreement with observations. Mayr et al. [1988] investigated Venus gravity waves using a spectral model and made many conclusions, the most relevant here being the wave amplitudes are a factor of 3 to 5 larger during the night than during the day and waves excited at $130 \mathrm{~km}$ are rapidly attenuated (both conclusions in agreement with observations). Alexander [1992] used a Venus gravity wave-drag parameterization to describe the thermospheric superrotation and found that small- to medium-scale gravity waves in the thermosphere can supply the necessary acceleration of the mean flow if the waves have predominately large westward phase speeds. Zhang et al. [1996] adapted the Fritts and Lu [1993] terrestrial gravity wave-drag scheme to Venus, which treats the full wave spectrum (i.e., is not monochromatic) and distributes wave momentum according to wave saturation principles; however, the Fritts and $L u$ [1993] scheme is no longer used in current terrestrial models [Lawrence, 1997] due to the extreme sensitivity of the parameterization to arbitrary limit parameters. Zhang et al. [1996] also argued that the superrotation in Venus' thermosphere was caused by vertically propagating gravity waves and was not a remnant of the lower atmosphere circulation. 
[12] In this paper, we use the gravity wave-drag scheme of Alexander and Dunkerton [1999] coupled with the VTGCM to model the momentum drag in the upper atmosphere of Venus that is responsible for decelerating the zonal winds. Unlike Rayleigh friction, this type of momentum drag is based on a direct physical mechanism (i.e., gravity waves). The gravity wave parameterizations are described in section 2; the VTGCM in section 3. VTGCM results are in section 4. The effect of wave parameters on wave breaking level is shown in section 5. Section 6 discusses the results.

\section{Gravity Wave-drag Parameterization}

[13] The gravity wave-drag scheme used here is described in Ortland and Alexander [2006]; Alexander and Dunkerton [1999] and is a hybrid of Lindzen [1981] and Lindzen and Holton [1968] gravity wave schemes. The breaking criterion is the same as Lindzen [1981]); namely, upward propagating waves break when

$$
\frac{\rho(z) k_{h}}{2 N(z)}(c-u(z))^{3}-B(c) d c<0,
$$

where $z$ is altitude, $\rho$ is the density, $N$ is the Brunt-Väisälä frequency, $u$ is the background velocity component in the direction of wave propagation (and thus differs from standard notation where $u$ represents the eastward component of the wind velocity), $k_{h}$ is the horizontal wave number, $c$ is the horizontal phase speed for gravity waves propagating in a given azimuthal direction, and $B$ is the momentum flux density. VIRTIS measurements indicate gravity wavelengths in the range of $90-400 \mathrm{~km} . k_{h}$ is set to $2 \pi / 300 \mathrm{~km}^{-1}$ since higher values (lower wavelengths) lead to too many waves undergoing total internal reflection. The wave spectrum amplitude is assumed to follow a Gaussian distribution (although in general the Alexander and Dunkerton [1999] scheme may be formulated with any distribution of amplitudes), given by

$$
B(c)=B_{o} \exp \left[-\left(\frac{c-c_{o}}{c_{w}}\right)^{2}\right],
$$

where $c_{o}$ is the center phase speed of the Gaussian, $B_{o}$ is the magnitude of the stress at $c=c_{o}$ (amplitude of the Gaussian), and $c_{w}$ is the $1 / e$-width of the spectrum. Note that the calculation (equation (2)) must be done separately in each direction (north, south, east, west), and these parameters may have different values in different directions. Waves are launched from the bottom level of the VTGCM $(\sim 70 \mathrm{~km})$, corresponding to the region near the cloud tops.

[14] High-frequency waves undergo total internal reflection when

$$
k_{h}|c-u(z)| \geq\left(\frac{N(z)^{2} k_{h}^{2}}{k_{h}^{2}+1 /(2 H(z))^{2}}\right)^{1 / 2},
$$

where $H$ is the scale height. These waves are removed from the spectrum and produce no drag.

[15] The present scheme deposits the momentum flux locally and totally (as a single model layer) like Lindzen and Holton [1968] at the breaking level $z(c)$ defined by equation (1). The inverse function $c(z)$ is the phase speed that breaks at level $z . c(z)$ is redefined as the maximum value of $c$ on the interval $z^{\prime} \leq z$, i.e., once a wave breaks it is removed from the spectrum at higher levels. The acceleration of the background flow is given by

$$
F_{G W}=\frac{\varepsilon}{\rho(z)} \frac{d c(z)}{d z} B(c(z))
$$

where $\varepsilon$ is the "intermittency" factor. A fraction $<1$ accounts for the fact that waves come in wave packets and are sporadically produced (e.g., for Earth, gravity waves get launched during a thunderstorm, which is restricted in space and time). A turbopause level $t_{\mathrm{lev}}=135 \mathrm{~km}$ [von Zahn et al., 1980] is imposed, and any remaining unbroken and unreflected waves deposit their wave flux at this level and above decaying by a factor $\exp \left(\left(z-t_{\text {lev }}\right) / 3\right)$ due to molecular diffusion.

[16] The Alexander and Dunkerton [1999]) scheme is different from the Zhang et al. [1996] gravity wave scheme that has already been developed for Venus. The latter is based on the Fritts and Lu [1993] scheme, which distributes wave dissipation energy as an exponential function of height at low levels, a constant value at high levels, and a transition region in between. The Fritts and $L u$ [1993] is no longer widely used by the terrestrial modeling community because it was subsequently found that the results depended too sensitively on arbitrary limits [Lawrence, 1997]. A similar behavior was found when coupled with the VTGCM (described in the next section).

\section{Venus Thermosphere General Circulation Model}

\subsection{Model Description}

[17] The VTGCM is a 3-D finite-difference hydrodynamic model of the Venus upper atmosphere [e.g., Bougher et al., $1988,1997,2008]$ that is based on the National Center for Atmospheric Research (NCAR) terrestrial Thermospheric Ionosphere General Circulation Model. The VTGCM solves the time-dependent primitive equations for the neutral upper atmosphere; temperature, neutral-ion densities, and threecomponent neutral winds. The model domain covers a $5^{\circ}$ by $5^{\circ}$ latitude-longitude grid, with 69 evenly spaced log-pressure levels in the vertical, extending from approximately $\sim 70$ to $300 \mathrm{~km}(\sim 70$ to $200 \mathrm{~km})$ at local noon (midnight).

[18] Formulations for $\mathrm{CO}_{2} 15 \mu \mathrm{m}$ cooling, wave drag, and eddy diffusion are parameterized within the VTGCM using standard aeronomical formulations. "Exact" (line-by-line radiative transfer model) $\mathrm{CO}_{2} 15 \mu \mathrm{m}$ cooling rates for a given temperature and composition profile are taken from Roldán et al. [2000]; cooling rates for the simulated VTGCM temperatures and species abundances are calculated (from these exact rates) based upon a slight modification of a parameterization scheme utilized previously [e.g., Bougher et al., 1986]. The corresponding $\mathrm{O}-\mathrm{CO}_{2}$ collisional relaxation rate adopted for typical benchmark VTGCM simulations is now $3 \times 10^{-12} \mathrm{~cm}^{3} \mathrm{~s}^{-1}$ at $300 \mathrm{~K}$ [Bougher et al., 1999]. This value provides strong $\mathrm{CO}_{2} 15 \mu \mathrm{m}$ cooling that is consistent with the use of EUV-UV heating efficiencies of $~ 20-22 \%$, which are in agreement with detailed offline heating efficiency calculations of Fox [1988]. The near-IR heating term is incorporated using offline simulated look-up tables, updated recently using Roldán et al. [2000] rates. The most notable 
consequence from updating the new IR rates is the doubling of the $4.3 \mu \mathrm{m}$ heating around $115 \mathrm{~km}$ on the dayside. These changes imply a warmer atmosphere closer to solar zenith angle (SZA) of 0 , and a corresponding enhancement of $\mathrm{CO}_{2}$ $15 \mu \mathrm{m}$ cooling within the VTGCM.

[19] During the spin-up phase, Rayleigh friction was prescribed in order to mimic general wave-drag effects on the mean flow according to

$$
F_{R F}=\lambda_{R F}\left(u-u_{S R}\right),
$$

where $F_{R F}$ is the drag force, $\lambda_{R F}$ is a damping rate, $u$ is the VTGCM calculated zonal wind, and $u_{S R}$ is the specified zonal wind speed to approximate the retrograde superrotating zonal (RSZ) wind [Bougher et al., 1988]. The maximum $u_{S R}$ value was set to $75 \mathrm{~m} \mathrm{~s}^{-1}$. The damping rate is expressed as

$$
\lambda_{R F}=\lambda_{o} \sqrt{\frac{p_{\text {break }}}{p}},
$$

where $\lambda_{o}$ is the maximum $\lambda_{R F}\left(\lambda_{o}=0.5 \times 10^{-4} \mathrm{~s}^{-1}\right), p_{\text {break }}=$ $2.24 \times 10^{-2} \mu$ bar is the breaking level, and $p$ is pressure. $\lambda_{R F}$ is referred to as the symmetric Rayleigh drag term; $u_{S R}$ is the asymmetric Rayleigh drag term. The $\lambda_{R F}$ and $u_{S R}$ terms are based upon empirical matches to Pioneer Venus Orbiter (PVO) and VEx observations that contain a specified exponential profile dependent on $\cos$ (latitude). The resulting $F_{R F}$ term is then added to the momentum equation. For more detail on the Rayleigh friction formulations, see Brecht et al. [2011].

[20] The eddy diffusion coefficient on the nightside is prescribed in the form $K=\frac{A}{\sqrt{n}}$ with units of $\mathrm{cm}^{2} \mathrm{~s}^{-1}$ where $n$ is the total number density and $A$ is a constant [von Zahn et al., 1979]. The nightside eddy diffusion has a prescribed maximum value of $1 \times 10^{7} \mathrm{~cm}^{2} \mathrm{~s}^{-1}$, and the dayside has a constant value for the entire upper atmosphere of $1 \times 10^{6} \mathrm{~cm}^{2} \mathrm{~s}^{-1}$. For more details about the VTGCM, see Brecht et al. [2011].

\subsection{Summary of "Mean" VTGCM Case Results}

[21] The results for this study are based upon a VTGCM "mean" case, which is representative of mean conditions during the VEx sampling period [see Brecht et al., 2011; Brecht et al., 2012], and are produced using a Rayleigh friction scheme to provide the best match with observations. Ideally, simulations with properly represented gravity waves will closely resemble this simulation and the observations. The VEx mean conditions are depicted by statistically averaged $\mathrm{NO}$ and $\mathrm{O}_{2}$ nightglow emission maps (observed emissions averaged spatially and temporally) [Gérard et al., 2008; Piccioni et al., 2009; Soret et al., 2012]. Specific parameters in the VTGCM are tuned to achieve this mean condition, which are given as follows: solar minimum fluxes (F10.7- $\mathrm{cm}=70$ units), the maximum nightside eddy diffusion coefficient $\left(1.0 \times 10^{-7} \mathrm{~cm}^{2} \mathrm{~s}^{-1}\right)$, and the wave-drag parameter $\left(0.9 \times 10^{-4} \mathrm{~s}^{-1}\right)$. This mean case produced a maximum NO UV nightglow emission near the equator at $108 \mathrm{~km}$. The calculated peak vertical intensity was $2.28 \mathrm{kR}$ (Rayleigh $=10^{6}$ photons $\mathrm{cm}^{2} \mathrm{~s}^{-1}$ into $4 \pi \mathrm{sr}$ ) with a hemispheric average intensity of $0.78 \mathrm{kR}$. The $\mathrm{O}_{2}$ IR nightglow emission was also calculated near the equator but at $102 \mathrm{~km}$. The $\mathrm{O}_{2} \mathrm{IR}$ nightglow emission peak vertical intensity for a three-body reaction $\left(\mathrm{O}+\mathrm{O}+\mathrm{CO}_{2}\right)$ yield of $75 \%$ was $2.19 \mathrm{MR}$ with a corresponding hemispheric average intensity of $0.53 \mathrm{MR}$.
These nightglow peak intensities are within the VEx observational ranges, and the hemispheric averages agree favorably with the VEx observations [Brecht et al., 2011].

[22] Monitoring and modeling the nightglow emission gives rise to an understanding of the global wind system. The VTGCM neutral zonal winds near the equator at the morning terminator were $-108 \mathrm{~m} \mathrm{~s}^{-1}$ at $110 \mathrm{~km},-166 \mathrm{~m} \mathrm{~s}^{-1}$ at $120 \mathrm{~km}$, and $150 \mathrm{~m} \mathrm{~s}^{-1}$ near $180 \mathrm{~km}$. The evening terminator winds were $112 \mathrm{~m} \mathrm{~s}^{-1}$ at $110 \mathrm{~km}, 191 \mathrm{~m} \mathrm{~s}^{-1}$ at $120 \mathrm{~km}$, and $289 \mathrm{~m} \mathrm{~s}^{-1}$ near $180 \mathrm{~km}$. The evening terminator winds are faster than the morning terminator winds because the wavedrag term, Rayleigh friction, is prescribed asymmetrically in local time in order to mimic the observed upper atmosphere RSZ winds. The prescribed RSZ winds are very weak $\left(<10 \mathrm{~m} \mathrm{~s}^{-1}\right)$ from $\sim 80 \mathrm{~km}$ to $112 \mathrm{~km}$, and above $110 \mathrm{~km}$ the emergence of modest RSZ winds approach $\sim 100 \mathrm{~m} \mathrm{~s}^{-1}$ above $\sim 130 \mathrm{~km}$. This RSZ profile is slightly different than the profile described in Brecht et al. [2011] due to the updated VTGCM temperatures. This RSZ profile is needed to produce the $\mathrm{O}_{2}$ IR nightglow peak intensity near midnight and the NO UV nightglow peak intensity to be positioned near 01:00 LT.

[23] The convergence of the global wind system on the nightside not only produces night airglow emission, but it also contributes to the nightside heat balance [Brecht et al., 2011]. As discussed previously, the $4.3 \mu \mathrm{m}$ heating on the dayside near $115 \mathrm{~km}$ and the corresponding day-to-night global circulation produces a downwelling component on the nightside, which results in dynamical heating near midnight. This mean simulation produces a maximum temperature on the nightside of $198 \mathrm{~K}$ at $104 \mathrm{~km}$ with a corresponding total dynamical heating rate of $71 \mathrm{Kday}^{-1}$. This nightside peak temperature is in accord with available spacecraft and ground based observations [Bertaux et al., 2007; Bailey et al., 2008; Brecht et al., 2011]. For more details on the mean case, parameters, or observations, see Brecht et al. [2011].

\section{Implementation and Results}

[24] We initialized the combination VTGCM/gravity wave-drag simulations from the VTGCM mean state (section 3.2) that had symmetric Rayleigh friction (i.e., $u_{S R}=0$ in equation (5)) during its spin-up phase. Figure 1 shows a longitude-height cross section of the zonal winds at latitude $2.5^{\circ}$ for this state. The zonal winds are symmetric in local time because of the symmetric Rayleigh friction. At the start of the combination VTGCM/gravity wave-drag simulations, the gravity wave-drag term was turned on. In the numerical gravity wave-drag scheme, $c$ is discretized into $n_{c}=1200$ bins of width $\Delta c=0.5 \mathrm{~m} \mathrm{~s}^{-1}$ centered on $c_{o} . n_{c}$ is sufficiently large enough for the effect of the waves to vary smoothly with phase speed, while small enough to maintain computational efficiency.

[25] Note that faster harmonics propagate with a greater horizontal tilt and can leave the model's vertical grid column (at a given horizontal resolution) while propagating to the top of the model. For them, the approximation of vertically propagating gravity waves is no longer suitable, and 1-D gravity wave $(\mathrm{GW})$ parameterizations are not applicable. The discussion of this issue in Yigit et al. [2008, 2009] shows that waves faster than $100 \mathrm{~m} \mathrm{~s}^{-1}$ should not be considered in 


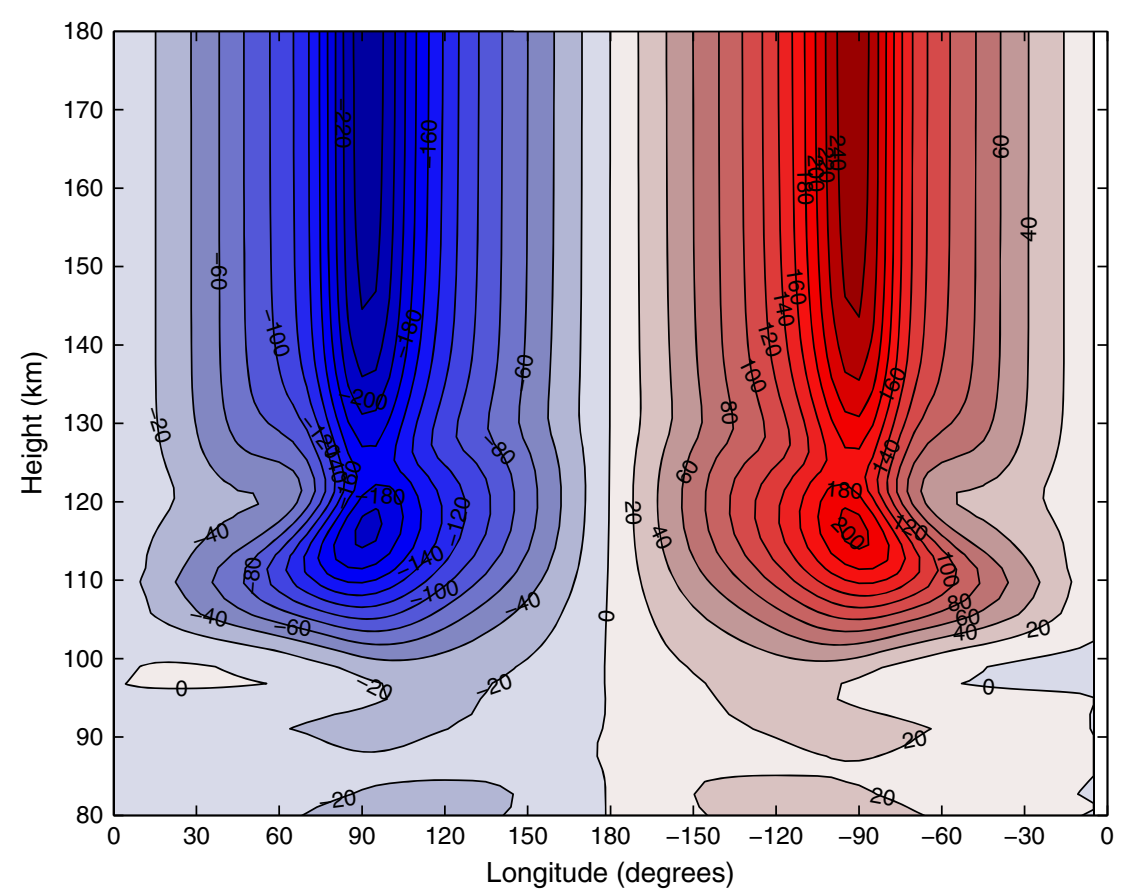

Figure 1. Initial VTGCM zonal winds $\left(\mathrm{m} \mathrm{s}^{-1}\right)$ at latitude $2.5^{\circ}$ with symmetric Rayleigh friction during spin-up. Gravity wave drag has not been turned on. The subsolar point (local time $12 \mathrm{~h}$ ) is at $180^{\circ}$ longitude. The morning and evening terminators are located at $90^{\circ}$ and $-90^{\circ}$ longitude, respectively.

column-based GW parameterizations. We have found in our model that waves with phase speeds greater than about 150 $160 \mathrm{~m} \mathrm{~s}^{-1}$ undergo total internal reflection no matter what values for the wavespectrum that we use (discussed below, also see section 5).

[26] Waves are assumed to be launched by clouds, and $c_{o}$ is set to the wind speed at the cloud tops. $B_{o}$ controls the initial amplitude of waves and must be large enough for waves to influence the atmosphere but not so large that waves break too low in the atmosphere.

[27] While there is some guidance for the choice of $B_{o}, c_{o}$, $c_{w}, \varepsilon$, and the launch level from terrestrial cases, the appropriate values for Venus are unknown. A wide range of parameters were tried. For $B_{o}$, values spanning many orders of magnitude, specifically $10^{-6}, 10^{-5}, 10^{-4}, 10^{-3}$, $10^{-2}, 10^{-1} \mathrm{~kg} \mathrm{~m}^{-2} \mathrm{~s}^{-1}$ and also finer increments of $0.0008,0.0009,0.0011,0.0012,0.002,0.003 \mathrm{~kg} \mathrm{~m}^{-2} \mathrm{~s}^{-1}$ were tried. For $c_{0}$, values of $0,10,20,30,45,90,180$, and $-90 \mathrm{~m} \mathrm{~s}^{-1}$ were tried in the zonal direction and 0,90 , and $180 \mathrm{~m} \mathrm{~s}^{-1}$ in the meridional direction. $c_{o}$ was also set to the local wind speed at the launch level, $u$ and $v$. For $c_{w}$, values of $40,80,90,120$, and $200 \mathrm{~m} \mathrm{~s}^{-1}$ were tried. Values for $\varepsilon$ were $0.0004167(1 / 2400), 0.0008333 \quad(1 / 1200)$, $0.0016667(1 / 600) 0.008,0.009,0.01$, and 0.1 . Launch levels ranged from the bottom level $(70 \mathrm{~km})$ of the VTGCM, $90 \mathrm{~km}, 100 \mathrm{~km}$, and from multiple levels from 70 to $90 \mathrm{~km}$ and 70 to $100 \mathrm{~km}$.

[28] Despite considering a very wide range of cases, no simulations provided a suitable match to VEx observations. Because the parameters are not linearly independent, we cannot conclude that it is impossible to find a working combination; however, we will show a range of cases that suggest it is unlikely. The description of the best case follows.
As a first demonstrating case (case 1), the gravity wave-drag parameters were set to $B_{o}=10^{-5} \mathrm{~kg} \mathrm{~m}^{-2} \mathrm{~s}^{-1}, c_{w}=80 \mathrm{~m} \mathrm{~s}^{-1}$, $c_{o}=0$, and $\varepsilon=1 / 1200$ for all azimuthal directions, and further integrated the model for 9 Earth days of model time. We have run the model simulations out to 63 Earth days but find no significant change from the 9 day results. Ideally, the gravity wave-drag scheme will perturb the mean state to a new steady state in which gravity waves provide additional momentum drag in the upper atmosphere. Figure 2 shows the resulting longitude-height cross section of the gravity wave drag, and Figure 3 shows the corresponding zonal winds. Westerly drag exists where there are easterly winds, and easterly drag exists where there are westerly winds. Drag is absent from the jet cores near the morning and evening terminators $\left(90^{\circ}\right.$ and $-90^{\circ}$ longitude, respectively) and above $110 \mathrm{~km}$ altitude. This is an undesirable result because winds must decelerate at all longitudes. Figure 4 is the difference in winds between the combination VTGCM/gravity wave-drag results and the symmetric Rayleigh friction winds (i.e., Figure 3 minus Figure 1). The locations of nonzero differences between these two winds occurs at the locations of nonzero gravity wave drag, as expected, but magnitudes of the zonal winds in the centers of the jet cores are hardly affected by the addition of gravity wave drag using this gravity wave parameter set.

[29] PVO and VEx observations of density and nightglow emissions, interpreted using general circulation models with Rayleigh friction [e.g., Bougher et al., 2008; Brecht et al., 2011], show that the zonal winds at the morning terminator (near $90^{\circ}$ longitude) should be weaker than on the evening terminator (near near $-90^{\circ}$ longitude). Figure 5 shows a VTGCM simulation with Rayleigh friction applied in a manner that is asymmetric in local time (i.e., $u_{S R} \neq 0$ in equation (5)). Gravity wave drag is turned off in this simulation. 


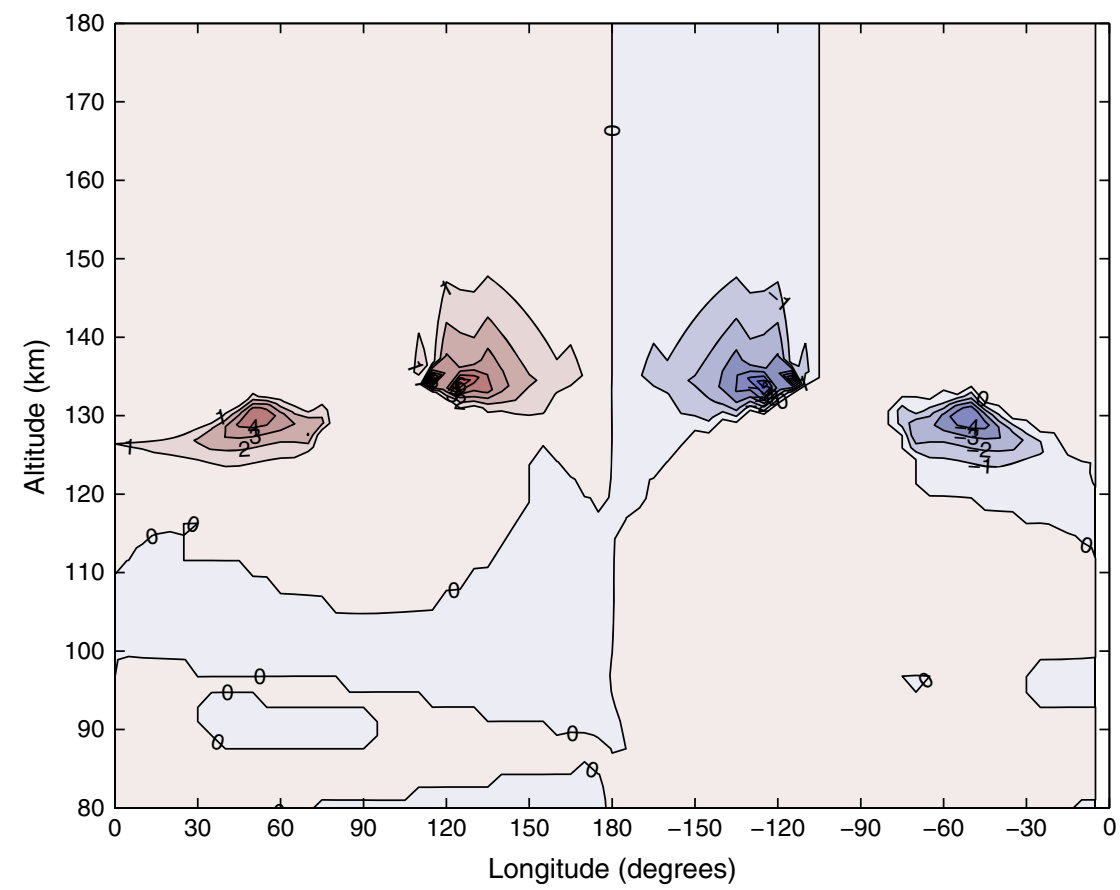

Figure 2. Instantaneous case 1 gravity wave drag $\left(10^{-3} \mathrm{~m} \mathrm{~s}^{-2}\right)$ at latitude $2.5^{\circ}$ after 9 Earth days of VTGCM/gravity wave-drag integration. The subsolar point (local time $12 \mathrm{~h}$ ) is at $180^{\circ}$ longitude. The morning and evening terminators are located at $90^{\circ}$ and $-90^{\circ}$ longitude, respectively. Contour intervals are $10^{-3} \mathrm{~m} \mathrm{~s}^{-2}$ with a maximum and minimum of $\pm 6 \times 10^{-3} \mathrm{~m} \mathrm{~s}^{-2}$.

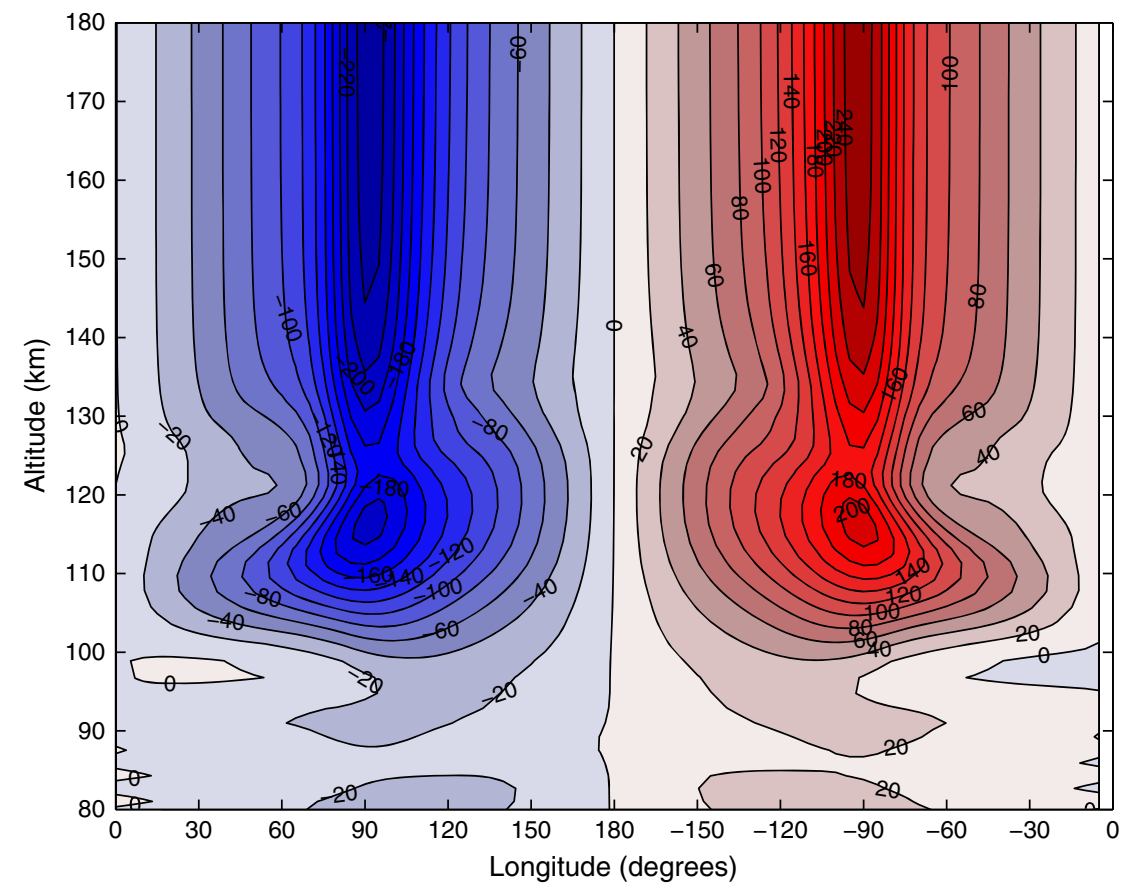

Figure 3. Instantaneous case 1 zonal winds $\left(\mathrm{m} \mathrm{s}^{-1}\right)$ at latitude $2.5^{\circ}$ after 9 Earth days of VTGCM/gravity wave-drag integration. The subsolar point (local time $12 \mathrm{~h}$ ) is at $180^{\circ}$ longitude. The morning and evening terminators are located at $90^{\circ}$ and $-90^{\circ}$ longitude, respectively.

[30] To obtain this wind pattern using gravity wave drag, the magnitude of the drag on the morning terminator (where the winds are easterly) must be stronger. The zonal $c_{o}$ was shifted to $90 \mathrm{~m} \mathrm{~s}^{-1}$ (as suggested by VEx observations at the cloud tops by Moissl et al. [2009]), such that the amplitude of the phase speed spectrum is weighted towards 


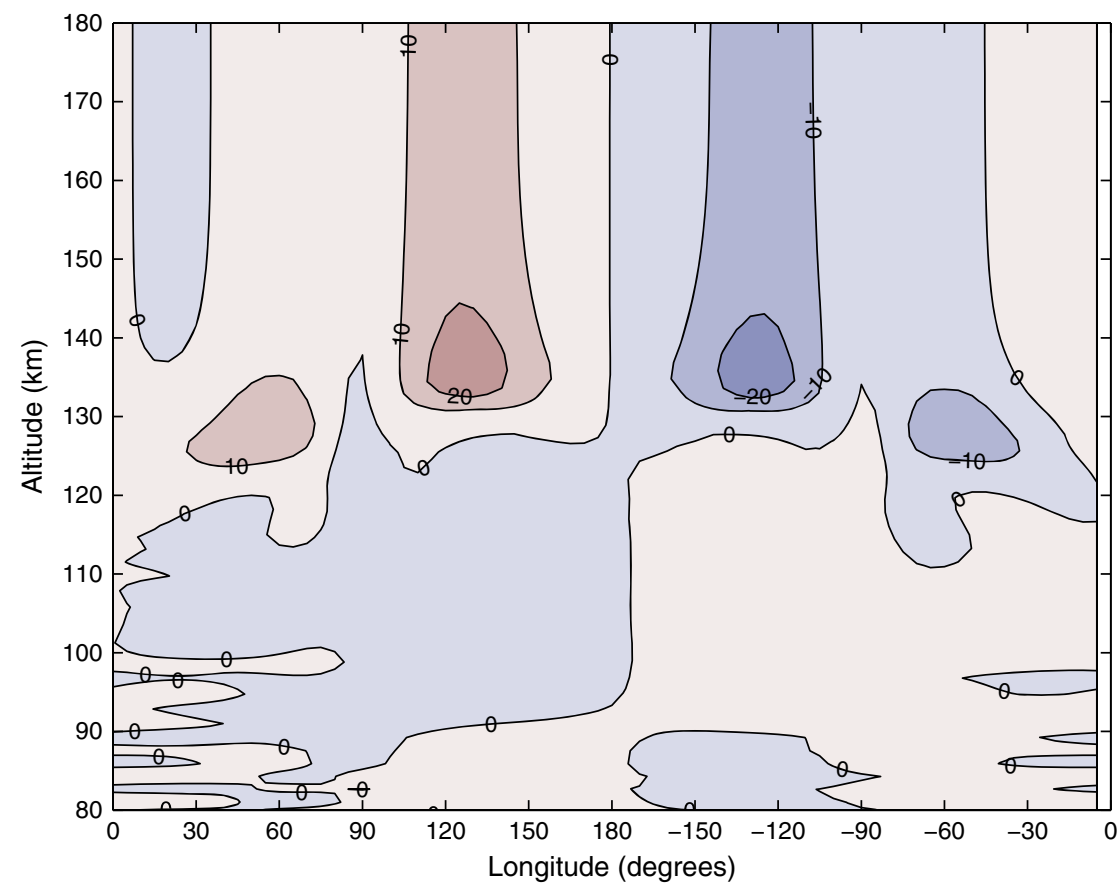

Figure 4. Difference between instantaneous case $1 \mathrm{VTGCM}$ /gravity wave-drag zonal winds and zonal winds with symmetric Rayleigh friction during spin-up $\left(\mathrm{m} \mathrm{s}^{-1}\right)$. Latitude is $2.5^{\circ}$. The VTGCM/gravity wave-drag model has been integrated for 9 Earth days, starting from the symmetric Rayleigh friction configuration. The subsolar point (local time $12 \mathrm{~h}$ ) is at $180^{\circ}$ longitude. The morning and evening terminators are located at $90^{\circ}$ and $-90^{\circ}$ longitude, respectively. There is a $\sim 20 \mathrm{~m} \mathrm{~s}^{-1}$ reduction in the winds near $135 \mathrm{~km}$ altitude and $\pm 130^{\circ}$ longitude and a $\sim 10 \mathrm{~m} \mathrm{~s}^{-1}$ reduction near $130 \mathrm{~km}$ altitude and $\pm 150^{\circ}$ longitude, but otherwise the wind magnitudes are unchanged in the jet cores $\left( \pm 90^{\circ}\right.$ and above $100 \mathrm{~km})$.

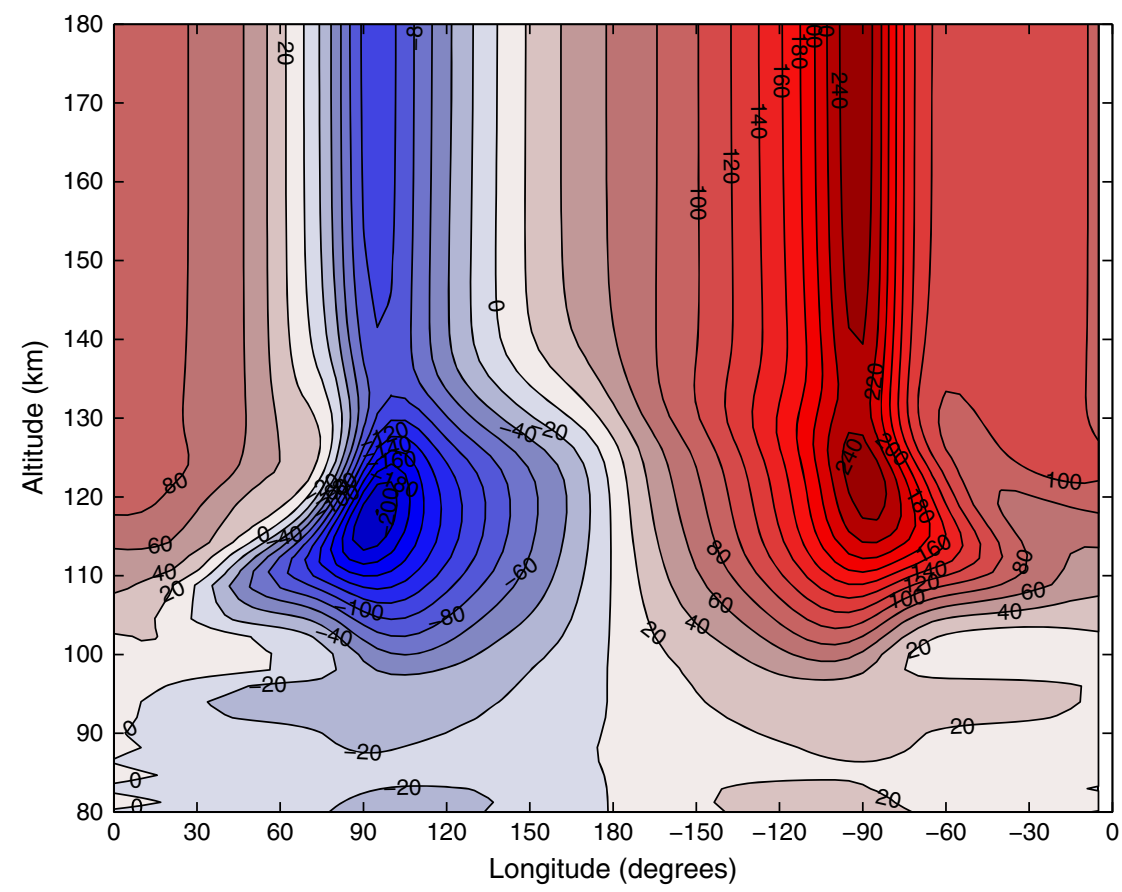

Figure 5. Initial VTGCM zonal winds $\left(\mathrm{m} \mathrm{s}^{-1}\right)$ at latitude $2.5^{\circ}$ and asymmetric Rayleigh friction. Gravity wave drag has not been turned on. The subsolar point (local time $12 \mathrm{~h}$ ) is at $180^{\circ}$ longitude. The morning and evening terminators are located at $90^{\circ}$ and $-90^{\circ}$ longitude, respectively. 
westerly waves and repeated the combination VTGCM/ gravity wave-drag simulations (case 2) starting from the symmetric spun up state (Figure 1). Figure 6 shows a longitude-height cross-section of the gravity wave drag, and Figure 7 shows the zonal winds after 9 Earth days of model integration with gravity wave drag turned on. The resulting drag force is now asymmetric in local time, as expected and desired. The magnitude of the zonal wind on the edges of the jet has been modified near the areas where there is nonzero gravity wave drag, but the drag in the jet core is insufficient. Figure 8 shows the difference between the VTGCM/gravity wave-drag zonal winds for case 2 and the zonal winds with asymmetric Rayleigh friction during spin-up. Significant $\left(\geq 100 \mathrm{~m} \mathrm{~s}^{-1}\right)$ deviations exist between the VTGCM/gravity wave-drag zonal wind results and the asymmetric wind pattern that has been shown to match data with asymmetric Rayleigh drag; the character of the asymmetry in the zonal wind structure needed to match VEx observations is not reproduced.

\section{Investigation of Breaking Level}

[31] Neither configuration of the combination VTGCM/ gravity wave drag from section 3 was able to produce drag that penetrated the jet core. Since this gravity wave-drag scheme has previously only been applied to Earth, we know the gravity wave parameterization must be tuned to achieve the best match of VTGCM output fields to VEx observations. The parameter space is large. Offline diagnostics of the gravity wave-drag scheme were performed to explore a wide range of parameter space and to develop an understanding of how the gravity wave-drag scheme affects the VTGCM results.
[32] Figure 9 shows a plot of breaking level versus wave phase speed and longitude (at $2.5^{\circ}$ latitude) from which information about the behavior of gravity wave drag may be inferred. The breaking level was calculated from equation (1) and using the VTGCM symmetric wind profile of Figure 1. The gravity wave-drag parameters are the same as case 1 from above. White areas indicate no waves have broken for a particular phase speed and longitude pair before total internal reflection occurred. Thus, the waves have not deposited any momentum in this column. This behavior occurs for positive phase speeds near $90^{\circ}$ longitudes, and negative phase speeds near $-90^{\circ}$ longitude, i.e., in the jet cores when phase speed and zonal wind are of different signs. It also occurs for very high-magnitude phase speed waves at any longitude. At $\pm 90^{\circ}$ longitude, when the phase speed and zonal wind are the same sign (first and third quadrants), the breaking level is defined but is low $(\leq 105 \mathrm{~km})$. At these low altitudes and higher atmospheric densities, the breaking waves have only a weak forcing effect.

[33] On the jet flanks $\left(0^{\circ}-45^{\circ}, 135^{\circ}-180^{\circ},-180^{\circ}-\left(-135^{\circ}\right)\right.$, and $-45^{\circ}-0^{\circ}$ longitude), waves of both signs break at higher altitudes. The gravity wave-drag force defined by equation (4) depends on both the amplitude of the waves as a function of phase speed and inversely on the density as a function of height. The combination of these parameters will determine the sign of the waves that dominate, and they are not easily read off of the wave breaking plots. No waves break above $135 \mathrm{~km}$ because we have defined the turbopause to be at this level, and all waves that penetrate this high are forced to decay exponentially with height above this location.

[34] Table 1 shows additional combinations of gravity wave parameters. Figure 10 shows the wave breaking height

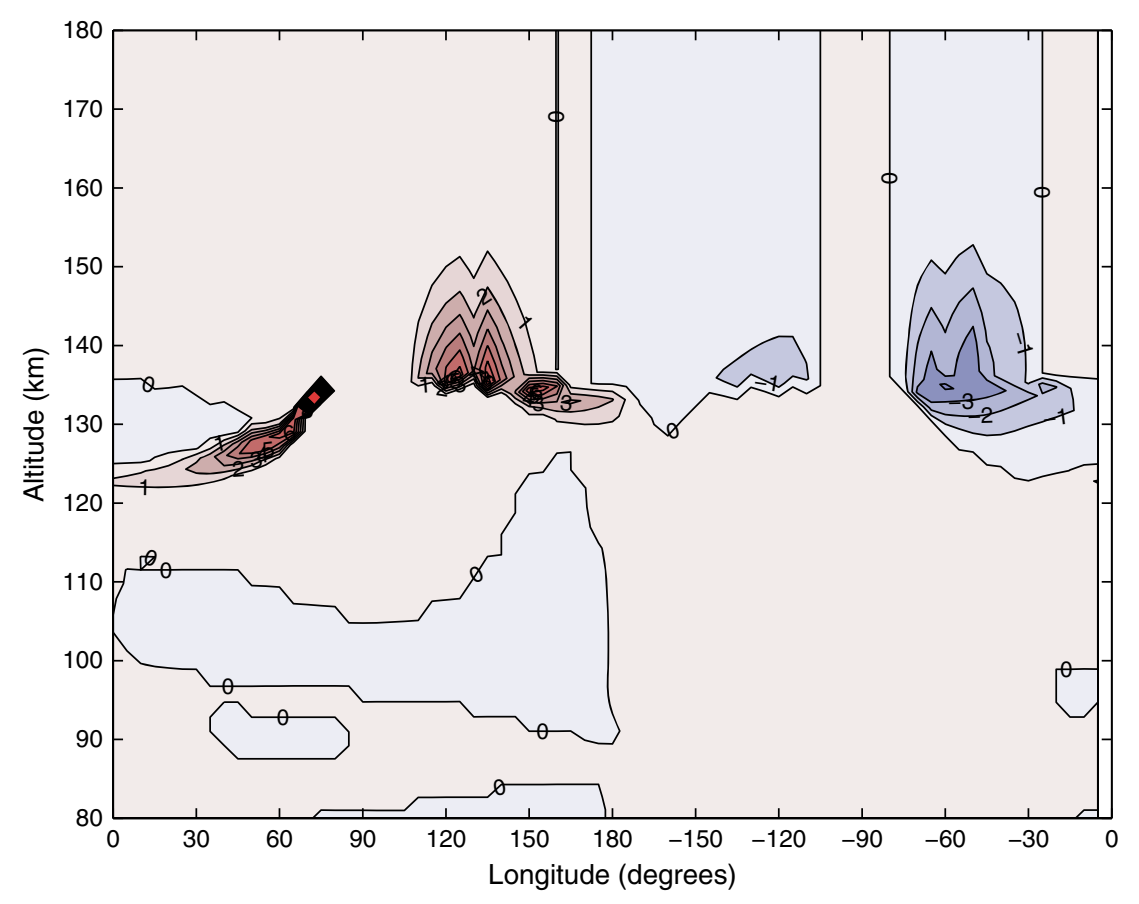

Figure 6. Instantaneous case 2 gravity wave drag $\left(10^{-3} \mathrm{~m} \mathrm{~s}^{-2}\right)$ at latitude $2.5^{\circ}$ after 9 Earth days of VTGCM/gravity wave-drag integration. The subsolar point (local time $12 \mathrm{~h}$ ) is at $180^{\circ}$ longitude. The morning and evening terminators are located at $90^{\circ}$ and $-90^{\circ}$ longitude, respectively. Contour intervals are $10^{-3} \mathrm{~m} \mathrm{~s}^{-2}$ with a maximum and minimum of $6 \times 10^{-3} \mathrm{~m} \mathrm{~s}^{-2}$ and $-4 \times 10^{-3} \mathrm{~m} \mathrm{~s}^{-2}$, respectively. 


\section{ZALUCHA ET AL.: GRAVITY WAVES IN A VENUS MODEL}

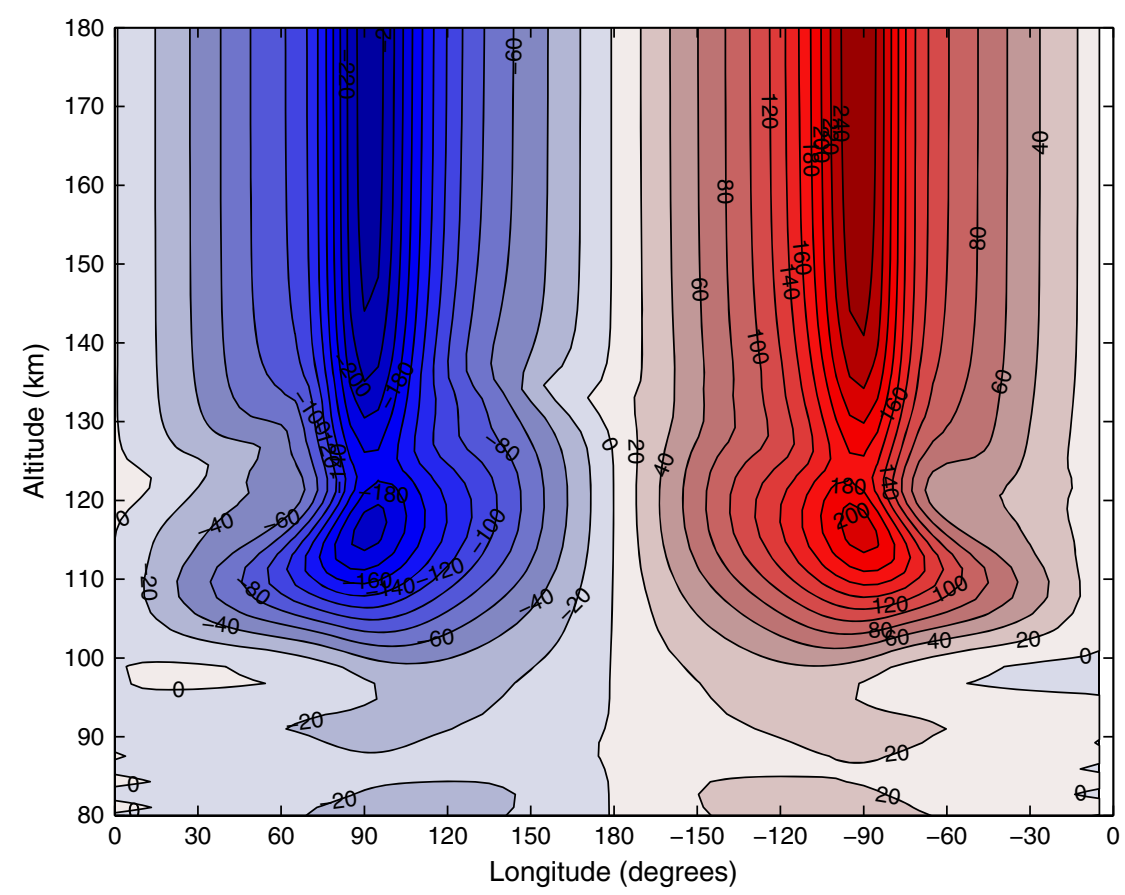

Figure 7. Instantaneous case 2 zonal winds $\left(\mathrm{m} \mathrm{s}^{-1}\right)$ at latitude $2.5^{\circ}$ after 9 Earth days of VTGCM/gravity wave-drag integration. The subsolar point (local time $12 \mathrm{~h}$ ) is at $180^{\circ}$ longitude. The morning and evening terminators are located at $90^{\circ}$ and $-90^{\circ}$ longitude, respectively.

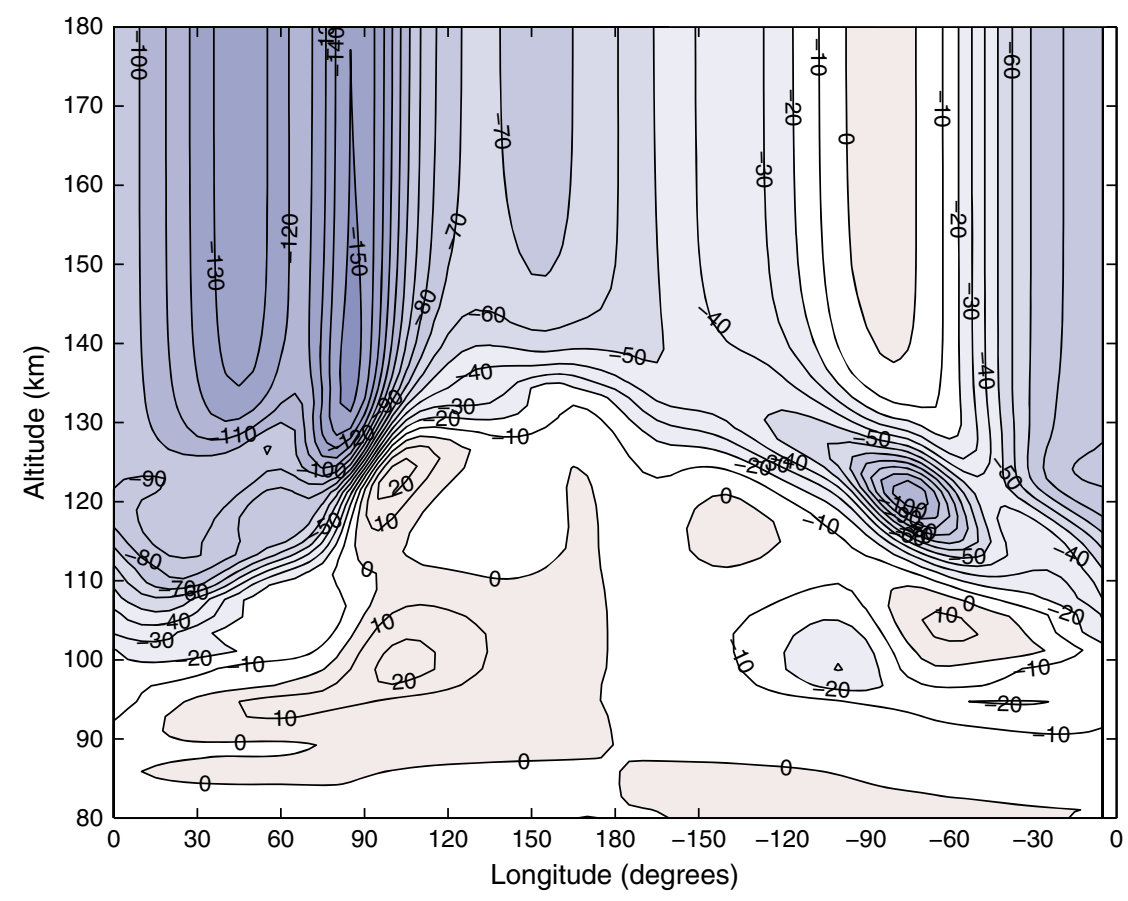

Figure 8. Difference between instantaneous case 2 zonal winds and zonal winds with asymmetric Rayleigh friction during spin-up $\left(\mathrm{m} \mathrm{s}^{-1}\right)$. Latitude is $2.5^{\circ}$. The VTGCM/gravity wave-drag model has been integrated for 9Earth days. The subsolar point (local time $12 \mathrm{~h}$ ) is at $180^{\circ}$ longitude. The morning and evening terminators are located at $90^{\circ}$ and $-90^{\circ}$ longitude, respectively. Significant $\left(\geq 100 \mathrm{~m} \mathrm{~s}^{-1}\right.$ differences occur at positive longitudes, indicating that the gravity wave drag has not produced enough change in the winds to slow them down there. 


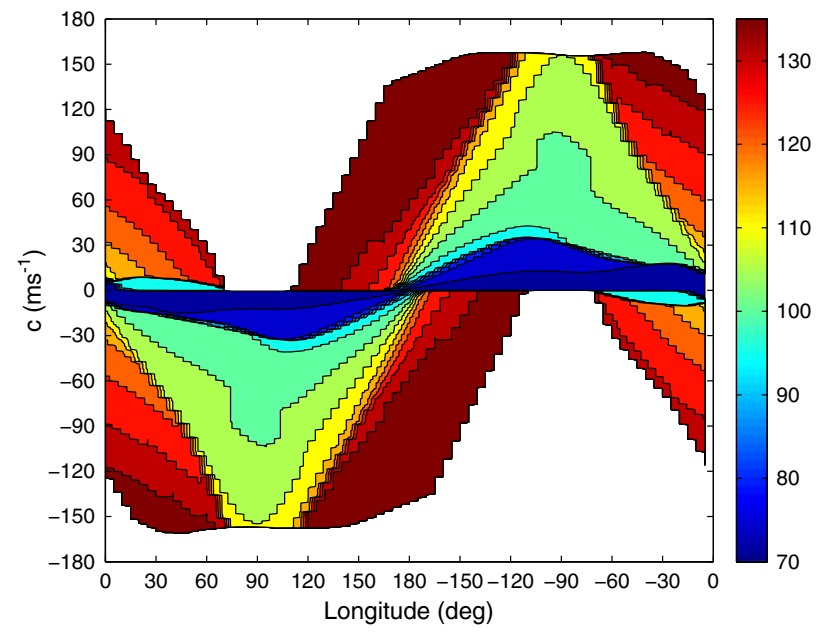

Figure 9. Gravity wave breaking level $(\mathrm{km})$ for case 1. Contour intervals are $5 \mathrm{~km}$. The morning and evening terminators are located at $90^{\circ}$ and $-90^{\circ}$ longitude, respectively.

Table 1. Parameter Sets for Wave Breaking Analysis

\begin{tabular}{lccc}
\hline Case & $B_{o}\left(\mathrm{~kg} \mathrm{~m}^{-2} \mathrm{~s}^{-1}\right)$ & $c_{o}\left(\mathrm{~m} \mathrm{~s}^{-1}\right)$ & $c_{w}\left(\mathrm{~m} \mathrm{~s}^{-1}\right)$ \\
\hline 1 & $10^{-5}$ & 0 & 80 \\
2 & $10^{-5}$ & 90 & 80 \\
3 & $10^{-8}$ & 0 & 80 \\
4 & $10^{-2}$ & 0 & 80 \\
5 & $10^{-5}$ & 0 & 40 \\
\hline
\end{tabular}

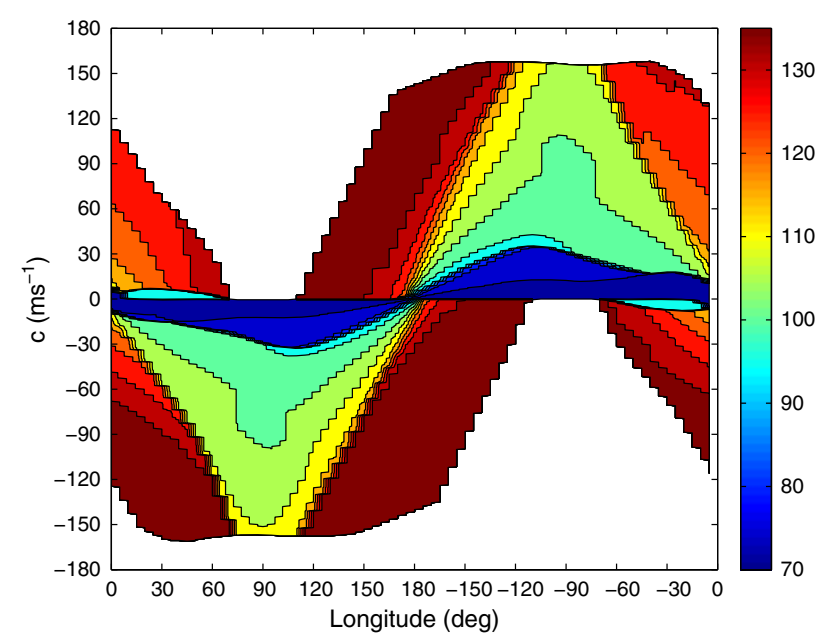

Figure 10. Gravity wave breaking level $(\mathrm{km})$ for case 2 . Contour intervals are $5 \mathrm{~km}$. The morning and evening terminators are located at $90^{\circ}$ and $-90^{\circ}$ longitude, respectively.

for case 2 (wave amplitude weighted towards westerly phase speeds). As in case 1 (symmetric wave amplitude), the jet cores either contain waves that break too low or undergo total internal reflection. The breaking level has increased in altitude for the negative phase speeds and decreased for the positive phase speeds in the flanks of the jets.

[35] Figure 11 shows the breaking level for the case with $B_{o}$ decreased by 3 orders of magnitude (case 3), while Figure 12

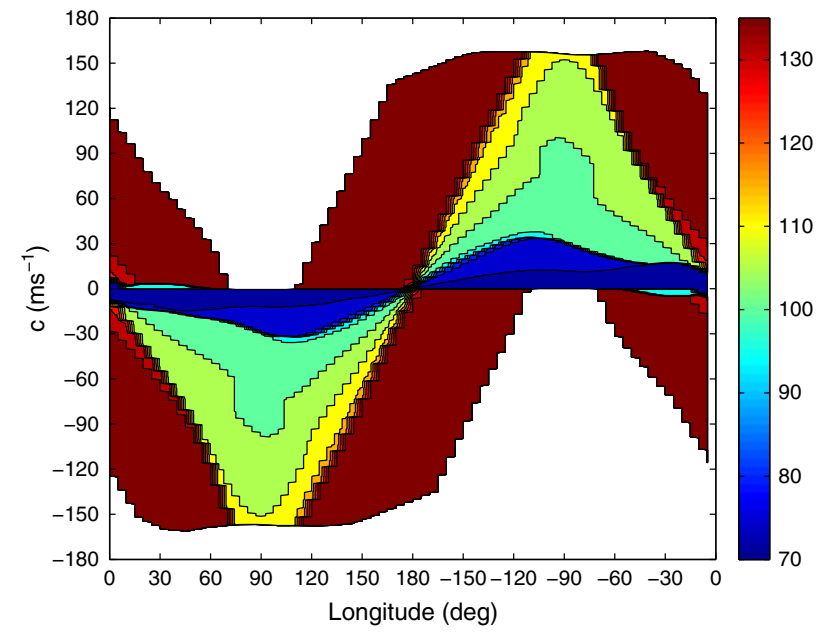

Figure 11. Gravity wave breaking level (km) for case 3. Contour intervals are $5 \mathrm{~km}$. The morning and evening terminators are located at $90^{\circ}$ and $-90^{\circ}$ longitude, respectively.

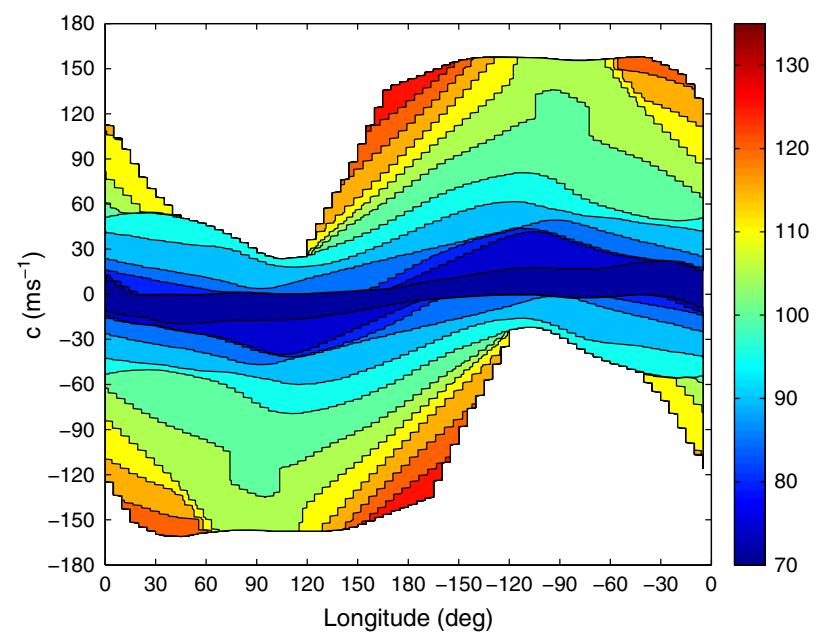

Figure 12. Gravity wave breaking level (km) for case 4 . Contour intervals are $5 \mathrm{~km}$. The morning and evening terminators are located at $90^{\circ}$ and $-90^{\circ}$ longitude, respectively.

shows the breaking level for the case with $B_{o}$ increased by 3 orders of magnitude. Comparing these along with case 1 shows that the breaking level decreases in altitude with increasing $B_{o}$ because the wave reaches critical amplitude lower in the atmosphere. Still, the waves at the longitudes of the jet cores either break too low or undergo total internal reflection. Figure 13 shows the breaking level for the case of $c_{w}$ decreased by a factor of 2 , which narrows the distribution of wave amplitudes. In the jet flanks, the wave breaking level decreases with decreasing $c_{w}$, and the jet cores remain untouched.

\section{Discussion}

[36] Rayleigh friction provides a source of momentum dissipation in general circulation models (GCMs); however, it does not have a physically grounded basis. Rayleigh friction is useful to provide a context for the magnitudes 


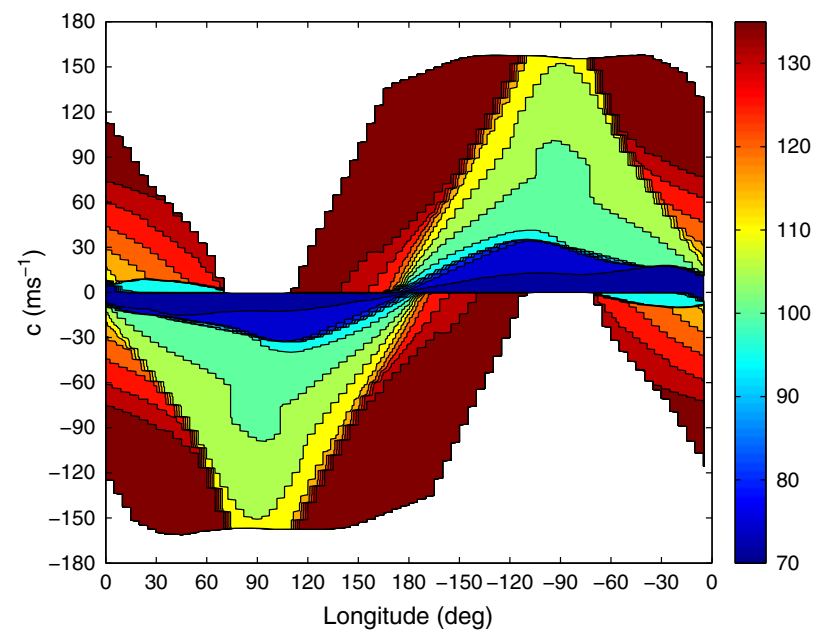

Figure 13. Gravity wave breaking level (km) for case 5 . Contour intervals are $5 \mathrm{~km}$. The morning and evening terminators are located at $90^{\circ}$ and $-90^{\circ}$ longitude, respectively.

and altitudes of momentum deposition needed in the upper atmosphere for reproducing VEx observations. Gravity waves launched from the cloud tops are a mechanism for depositing momentum when they propagate upwards, then become unstable and break. Gravity waves are small in spatial and temporal scales compared with the resolution of a GCM. Therefore, some parameterization is still needed.

[37] Although there are several different gravity wave parameterizations in common use in Earth middle atmosphere models, McLandress and Scinocca [2005] showed that these can all be tuned to give rather similar results. One difference among these parameterizations is whether or not they include the process of total internal reflection. The Alexander and Dunkerton [1999] parameterization includes this process. Others do not, although Scinocca [2002] described a method for adding the process to the Warner and McIntyre [2001] parameterization, and this modified parameterization is now in use at the European Center for Medium Range Weather Forecasting [Orr et al., 2010]. Our results suggest that if we chose a different parameterization for Venus that does not include reflection, that while we might obtain drag in the jet cores, this would be spuriously due to the absence of this apparently important process.

[38] The gravity wave-drag scheme presented in Alexander and Dunkerton [1999] (and later Ortland and Alexander [2006]) has been successfully used in Earth upper atmosphere models. Venus has very high-speed thermospheric jets on the morning and evening terminators that in the absence of any momentum drag produce strong winds that are inconsistent with VEx observations. Three key parameters need to be adjusted for application to Venus: the initial amplitude of the gravity wave spectrum $B_{o}$, the spectrum width $c_{w}$, and the offset of phase speeds $c_{o}$. The first two parameters have less connection to a large-scale, model-resolved physical parameter, while we interpret $c_{o}$ to be related to the model background wind speed at the launch level (in this case, the cloud tops). $B_{o}, c_{o}$, and $c_{w}$ were varied over a large area of parameter space, namely, $B_{o}=10^{-8}$ to $10^{-2} \mathrm{~kg} \mathrm{~m}^{-2} \mathrm{~s}^{-1}, c_{o}=0$ to $90 \mathrm{~m} \mathrm{~s}^{-1}$, and $c_{w}=40$ to $80 \mathrm{~m} \mathrm{~s}^{-1}$, the results of which were presented in section 5 , as well as various combinations of these parameters and more extreme values. In every case, within the morning and evening terminator jets, the waves either are totally internally reflected, thus prohibiting them from breaking and depositing any momentum or breaking at too low an altitude $(\leq 105 \mathrm{~km})$ where the winds are weak. The low-level shear is too great for waves of any physically plausible configuration to propagate upwards into the highspeed regions of the jets to potentially decelerate the winds.

[39] The version of the Alexander and Dunkerton [1999] gravity wave-drag scheme implemented in the VTGCM was able to modify the winds in the jet flanks, but is peripheral to the main goal of decelerating the winds in the jet core. It was found that lower $B_{o}$ corresponds to higher breaking level, for reasons as follows. The background atmospheric density decreases with height, while wave amplitude grows with decreasing density. Waves propagate upwards until the density becomes low enough that they are no longer in the linear (stable) regime and therefore break. A group of waves that have an initially lower amplitude (lower $B_{o}$ ) will be able to propagate to lower densities (higher altitudes) before breaking. This behavior is represented mathematically in the breaking equations, equation (2). $\rho, u$, and $N$ all depend on $z$, but the $\rho$ factor is the strongest because it has an exponential dependence. Thus, a lower $B_{o}$ results in a smaller $\rho$ (higher $z$ ) when the left side of the equation reaches 0 .

[40] It was also found that lower $c_{w}$ corresponds to lower breaking level. $c_{w}$ controls the width of the initial amplitude distribution; lower $c_{w}$ makes the distribution narrower. For a given phase speed $c$, lower $c_{w}$ causes the initial amplitude of that particular wave to be decreased (except at the center of the distribution $c=c_{o}$ where the initial amplitude remains the same). Lower initial wave amplitude corresponds to higher breaking level, for the same arguments as above.

[41] For a wind distribution that is symmetric in local time, shifting $c_{o}$ off of 0 causes the breaking level to be asymmetric in local time. $c_{o}$ controls the phase speed where the maximum initial wave amplitude occurs. The breaking of each wave is controlled by its phase speed relative to the background wind. For $c_{o}=0$, waves with opposite signed phase speeds will have the same initial amplitude and same relative speed with respect to the background wind and will thus break at the same level (but with opposite signed drag). For $c_{o} \neq 0$, the distribution of amplitudes is not symmetric about $c=0$. Thus, waves with opposite signed phase speeds will now have different initial amplitudes and different breaking levels.

[42] The intermittency factor $\varepsilon$ enters into the force equation but not the breaking level. $\varepsilon$ is a factor between 0 and 1 that allows for gravity waves that are not necessarily being produced continuously at all times. $\varepsilon$ can be increased or decreased to produce the desired force of the gravity waves as $B_{o}$ is changed. However, since no waves are penetrating the jet cores, the force is zero, and $\varepsilon$ is not relevant.

[43] Several parameters have remained fixed in the analysis. The launch level is always taken to be the cloud tops at the base of the VTGCM. Presumably, the source of the gravity waves is mesoscale convection in the clouds that penetrates into stable layers. We have tried to raise the launch level to $100 \mathrm{~km}$, but then the waves that would have broken in the $70-100 \mathrm{~km}$ region break at $100 \mathrm{~km}$ instead, which is still too low to affect the jet cores. The wave breaking criteria above $100 \mathrm{~km}$ is still the same, and the behavior above unchanged 
from the $70 \mathrm{~km}$ launch level case within the jet core magnitudes. While we were unable to obtain realistic drag with gravity wave launched at cloud levels, it is possible that secondary waves may be a source for waves at higher altitudes. For example, cloud top waves may break in the strong shear zones between 100 and $115 \mathrm{~km}$ and generate secondary waves, which can subsequently penetrate into the jet cores and give the drag forces needed to slow the winds.

\section{Conclusion}

[44] We have implemented a gravity wave-drag scheme based on Alexander and Dunkerton [1999]; Ortland and Alexander [2006] for use in the VTGCM. We have explored a number of wave parameters over a large parameter space but are unable to obtain gravity waves that propagate to sufficiently high altitudes within the morning and evening terminator jets. Total internal reflection occurs within the jet cores due to the high zonal wind speeds in those locations, which prevents waves from breaking and providing the necessary momentum damping as inferred from VEx observations of density and nightglow emissions. Thus, a different representation of the drag force by another gravity wave-drag scheme would still be unsuccessful if total internal reflection were present in the model. Other parameterizations that neglect total internal reflection might allow waves to propagate and break into the jet core, but only because this important process is neglected. Thus, parameterizations developed for the middle atmosphere are not appropriate for thermosphere and other damping mechanisms besides nonlinear breaking/saturation dominate and should be accounted for at these heights.

[45] Prior to our work with Alexander and Dunkerton [1999], we used a scheme described in Zhang et al. [1996], which is based on a model for terrestrial gravity waves by Fritts and Lu [1993]. This method assumes a spectrum of waves with a non-Gaussian functional form and assumes that waves deposit energy throughout the atmosphere. At low levels, the wave energy is exponentially dependent on height, then transitions to an expression for wave energy that is constant with height at upper levels. This scheme is no longer in wide use in Earth GCMs, and we found it difficult to tune because small changes in model parameters would lead to nearly random distributions of drag.

[46] Vertically propagating waves perturb the atmosphere, producing adjacent layers of different temperatures. A warm layer between two colder layers will cool faster (i.e., produce more IR radiation) than if the layers were of equal temperature. Such IR cooling homogenizes the layers and dissipates vertically propagating waves, thus providing another mechanism for momentum deposition. On Earth, this process is still secondary to wave breaking [Marks and Eckermann, 1995]. On Mars in the upper atmosphere (for the $15 \mu \mathrm{m}$ $\mathrm{CO}_{2}$ band), it is of primary importance compared to wave breaking and molecular viscous damping [Eckermann et al., 2011] for waves whose source-level vertical wavelengths are $\leq 10-15 \mathrm{~km}$. Imamura and Ogawa [1995] show radiative damping rates for Venus as a function of vertical wavelength and altitude. The waves in the jet core that would be needed to slow the winds would have extremely long vertical wavelengths and hence very small radiative damping rates.
Hence, the addition of this process is not likely to assist in weakening the overly strong jets in the Venus thermosphere.

[47] Medvedev et al. [2011] and Medvedev and Yi it [2012] recently adapted a thermospheric gravity wave parameterization to Mars from a terrestrial scheme by Yiğit et al. [2008], which includes the effects of gravity wave saturation and breaking, gravity wave dissipation due to molecular viscosity, thermal conduction, ion drag, and radiative damping. The Medvedev et al. [2011] gravity wave saturation and breaking scheme is a spectral parameterization that distributes the wave amplitudes as a Gaussian over phase speeds with the same free parameters $c_{o}, B_{o}$, and $c_{w}$ as in Alexander and Dunkerton [1999] (our equation (2)). The Medvedev et al. [2011] and Medvedev and Yi it [2012] scheme is different than the Alexander and Dunkerton [1999] scheme in that the waves can be saturated at multiple heights and are not completely removed at a single breaking level. However, since we have shown that gravity waves are unable to propagate to high levels due to total internal reflection or breaking at low levels, the gravity wave saturation and breaking specifications of Medvedev et al. [2011] and Medvedev and $Y i$ it [2012] would not be effective momentum flux deposition mechanisms in the VTGCM. Moreover, the role of the radiative damping used in their model is in fine tuning and shaping the momentum deposition patterns.

[48] Currently, the bottom boundary condition of the VTGCM is static, but a time-varying boundary condition (at fixed pressure) in temperature, 3-D winds, and height surfaces would enable upward propagating planetary waves and tides to be present to reduce the strong shear in the $100-115 \mathrm{~km}$ layer. This might allow the parameterized gravity waves to penetrate the jet core without reflection and slow the winds in the thermosphere. The gravity wavedrag model would then be applied as described here. Hence, we would be considering a combination of dynamic processes rather than addressing them in isolation from one another.

[49] We noted secondary wave generation might be another important process in the Venus atmosphere that could provide the needed drag on thermospheric winds. One additional process that is neglected in gravity wave parameterizations but could be important on Venus is horizontal wave propagation. Sato et al. [2012] describe how this process can focus wave momentum into the jet core of the Earth's middle atmosphere, and if something similar occurs on Venus, it could also assist in slowing the thermospheric winds.

[50] Acknowledgments. This work was supported by the NASA Venus Express Participating Scientist Program, NNX10AI35G.

\section{References}

Alexander, M. J. (1992), A mechanism for the Venus thermospheric superrotation, Geophys. Res. Lett., 19, 2207-2210, doi:10.1029/92GL02110. Alexander, M. J., and T. J. Dunkerton (1999), A spectral parameterization of mean-flow forcing due to breaking gravity waves, J. Atmos. Sci., 56, 4167-4182, doi:10.1175/1520-0469(1999)056<4167:ASPOMF > 2.0. $\mathrm{CO} ; 2$.

Bailey, J., S. Chamberlain, D. Crisp, and V. S. Meadows (2008), Near infrared imaging spectroscopy of Venus with the Anglo-Australian Telescope, Planet. Space Sci., 56, 1385-1390, doi:10.1016/j.pss.2008.03.006.

Belton, M. J. S., G. R. Smith, D. A. Elliott, K. Klaasen, and G. E. Danielson (1976a), Space-time relationships in the UV markings on Venus, J. Atmos. Sci., 33, 1383-1393, doi:10.1175/1520-0469(1976)033<1383: STRITU > 2.0.CO;2. 


\section{ZALUCHA ET AL.: GRAVITY WAVES IN A VENUS MODEL}

Belton, M. J. S., G. R. Smith, G. Schubert, and A. D. del Genio (1976b), Cloud patterns, waves, and convection in the Venus atmosphere, in Bulletin of the American Astronomical Society, Bulletin of the American Astronomical Society, vol. 8, p. 486.

Belton, M. J. S., G. R. Smith, G. Schubert, and A. D. del Genio (1976c), Cloud patterns, waves and convection in the Venus atmosphere, J. Atmos. Sci., 33, 1394-1417, doi:10.1175/1520-0469(1976)033 < 1394:CPWACI 2.0.CO;2.

Bertaux, J.-L., et al. (2007), A warm layer in Venus' cryosphere and highaltitude measurements of $\mathrm{HF}, \mathrm{HCl}, \mathrm{H}_{2} \mathrm{O}$ and $\mathrm{HDO}$, Nature, 450, 646-649, doi:10.1038/nature05974.

Bougher, S. W., R. E. Dickinson, E. C. Ridley, R. G. Roble, A. F. Nagy, and T. E. Cravens (1986), Venus mesosphere and thermosphere. II-Global circulation, temperature, and density variations, Icarus, 68, 284-312, doi:10.1016/0019-1035(86)90025-4.

Bougher, S. W., R. G. E. Roble, R. E. Dickinson, and E. C. Ridley (1988), Venus mesosphere and thermosphere. III-Three-dimensional general circulation with coupled dynamics and composition, Icarus, 73, 545-573, doi:10.1016/0019-1035(88)90064-4.

Bougher, S. W., M. J. Alexander, and H. G. Mayr (1997), Upper atmosphere dynamics: Global circulation and gravity waves, in Venus II: Geology, Geophysics, Atmosphere, and Solar Wind Environment, edited by S. W. Bougher, D. M. Hunten, \& R. J. Phillips, pp. 259-291.

Bougher, S. W., S. Engel, R. G. Roble, and B. Foster (1999), Comparative terrestrial planet thermospheres 2 . Solar cycle variation of global structure and winds at equinox, J. Geophys. Res., 104, 16,591-16,611, doi:10.1029/1998JE001019.

Bougher, S. W., P. Blelly, M. Combi, J. L. Fox, I. Mueller-Wodarg, A. Ridley, and R. G. Roble (2008), Neutral upper atmosphere and ionosphere modeling, Space Sci. Rev., 139, 107-141, doi:10.1007/s11214-008-9401-9.

Brecht, A., S. Bougher, J.-C. Gérard, and L. Soret (2012), Atomic oxygen distributions in the Venus thermosphere: Comparisons between Venus Express observations and global model simulations, Icarus, 217(2), 759-766, doi:10.1016/j.icarus.2011.06.033.

Brecht, A. S., S. W. Bougher, J.-C. Gérard, C. D. Parkinson, S. Rafkin, and B. Foster (2011), Understanding the variability of nightside temperatures, $\mathrm{NO} \mathrm{UV}$ and $\mathrm{O}_{2}$ IR nightglow emissions in the Venus upper atmosphere, J. Geophys. Res., 116(E15), 8004, doi:10.1029/2010JE003770.

Covey, C., and G. Schubert (1982), Planetary-scale waves in the Venus atmosphere, J. Atmos. Sci., 39, 2397-2413, doi:10.1175/1520-0469 $(1982) 039<2397:$ PSWITV $>2.0$. CO; 2 .

Covey, C. C., and G. Schubert (1981a), Mesoscale convection in the clouds of Venus, Nature, 290, 17-20, doi:10.1038/290017a0.

Covey, C. C., and G. Schubert (1981b), 4-day waves in the Venus atmosphere, Icarus, 47, 130-138, doi:10.1016/0019-1035(81)90097-X.

Dunkerton, T. J. (1989), Theory of internal gravity wave saturation, Pure Appl. Geophys., 130, 373-397, doi:10.1007/BF00874465.

Eckermann, S. D., J. Ma, and X. Zhu (2011), Scale-dependent infrared radiative damping rates on Mars and their role in the deposition of gravity-wave momentum flux, Icarus, 211, 429-442, doi:10.1016/j. icarus.2010.10.029.

Fox, J. L. (1988), Heating efficiencies in the thermosphere of Venus reconsidered, Planet. Space Sci., 36, 37-46, doi:10.1016/0032-0633(88) 90144-4.

Fritts, D. C. (1984), Gravity wave saturation in the middle atmosphere-A review of theory and observations, Rev. Geophys. Space Phys., 22, 275-308.

Fritts, D. C., and W. Lu (1993), Spectral estimates of gravity wave energy and momentum fluxes. Part 2: Parameterization of wave forcing and variability, J. Atmos. Sci., 50, 3695-3713, doi:10.1175/1520-0469 (1993) $050<3695$ :SEOGWE $>2.0$. CO; 2 .

Fritts, D. C., L. Wang, J. Werne, T. Lund, and K. Wan (2009), Gravity wave instability dynamics at high Reynolds numbers. Part I: Wave field evolution at large amplitudes and high frequencies, J. Atmos. Sci., 66, 1126-1148, doi:10.1175/2008JAS2726.1.

Garcia, R. F., P. Drossart, G. Piccioni, M. López-Valverde, and G. Occhipinti (2009), Gravity waves in the upper atmosphere of Venus revealed by $\mathrm{CO}_{2}$ nonlocal thermodynamic equilibrium emissions, J. Geophys. Res. (Planets), 114(E13), E00B32, doi:10.1029/2008JE003073.

Gérard, J.-C., et al. (2008), Distribution of the $\mathrm{O}_{2}$ infrared nightglow observed with VIRTIS on board Venus Express, Geophys. Res. Lett., 35, L02,207, doi:10.1029/2007GL032021.

Holton, J. R. (1982), The role of gravity wave induced drag and diffusion in the momentum budget of the mesosphere, J. Atmos. Sci., 39, 791-799, doi:10.1175/1520-0469(1982)039<0791:TROGWI > 2.0.CO;2.

Imamura, T., and T. Ogawa (1995), Radiative damping of gravity waves in the terrestrial planetary atmospheres, Geophys. Res. Lett., 22, 267-270, doi:10.1029/94GL02998.

Kasprzak, W. T., A. E. Hedin, H. G. Mayr, and H. B. Niemann (1988), Wavelike perturbations observed in the neutral thermosphere of Venus, J. Geophys. Res., 93, 11,237-11,245, doi:10.1029/JA093iA10p11237.
Kasprzak, W. T., H. B. Niemann, A. E. Hedin, and S. W. Bougher (1993), Wave-like perturbations observed at low altitudes by the Pioneer Venus Orbiter Neutral Mass Spectrometer during orbiter entry, Geophys. Res. Lett., 20, 2755-2758, doi:10.1029/93GL02628.

Kim, Y.-J., S. D. Eckermann, and H.-Y. Chun (2003), An overview of the past, present and future of gravity-wave drag parametrization for numerical climate and weather prediction models, Atmos. Ocean, 41, 65-98, doi:10.3137/ao.410105.

Lawrence, B. (1997), The effect of parameterized gravity wave drag on simulations of the middle atmosphere during northern winter 1991/ 1992 - general evolution, in NATO ASI Series, Vol I 50: Gravity Wave Processes: Their Parameterization in Global Climate Models, edited by K. Hamilton, pp. 291-307, Springer-Verlag, New York.

Leovy, C. (1964), Simple models of thermally driven mesopheric circulation, J. Atmos. Sci., 21, 327-341, doi:10.1175/1520-0469(1964)021<0327: SMOTDM $>2.0 . \mathrm{CO} ; 2$.

Limaye, S. S. (1990), Venus: Thermal tides in the Venera 15 Fourier spectrometer data between $300-1300 \mathrm{~cm}^{-1}$, in Bulletin of the American Astronomical Society, BAAS, vol. 22, p. 1052.

Lindzen, R. S. (1981), Turbulence and stress owing to gravity wave and tidal breakdown, J. Geophys. Res., 86, 9707-9714, doi:10.1029/ JC086iC10p09707.

Lindzen, R. S. (1985), Multiple gravity-wave breaking levels, J. Atmos. Sci., 42, 301-305, doi:10.1175/1520-0469(1985)042<0301:MGWBL 2.0.CO;2.

Lindzen, R. S., and J. R. Holton (1968), A theory of the quasi-biennial oscillation, J. Atmos. Sci., 25, 1095-1107, doi:10.1175/1520-0469 (1968)025 < 1095:ATOTQB > 2.0.CO;2.

Markiewicz, W. J., et al. (2007), Morphology and dynamics of the upper cloud layer of Venus, Nature, 450, 633-636, doi:10.1038/nature06320.

Marks, C. J., and S. D. Eckermann (1995), A three-dimensional nonhydrostatic ray-tracing model for gravity waves: Formulation and preliminary results for the middle atmosphere, J. Atmos. Sci., 52, 1959-1984, doi:10.1175/15200469(1995)052 < 1959:ATDNRT > 2.0.CO;2.

Mayr, H. G., I. Harris, W. T. Kasprzak, M. Dube, and F. Varosi (1988), Gravity waves in the upper atmosphere of Venus, J. Geophys. Res., 931, 11,247-11,262, doi:10.1029/JA093iA10p11247.

McLandress, C., and J. F. Scinocca (2005), The GCM response to current parameterizations of non-orographic gravity wave drag, J. Atmos. Sci., 62, 2394-2413.

Medvedev, A. S., and E. Yi it (2012), Thermal effects of internal gravity waves in the Martian upper atmosphere, Geophys. Res. Lett., 39, L05201, doi:10.1029/2012GL050852.

Medvedev, A. S., E. Yiğit, P. Hartogh, and E. Becker (2011), Influence of gravity waves on the martian atmosphere: General circulation modeling, J. Geophys. Res. - Planets, 116(E15), 10,004, doi:10.1029/2011JE003848.

Moissl, R., et al. (2009), Venus cloud top winds from tracking UV features in Venus Monitoring Camera images, J. Geophys. Res., 114(E13), E00B31, doi:10.1029/2008JE003117.

Orr, A., P. Bechtold, J. Scinocca, M. Ern, and M. Janiskova (2010), Improved middle atmosphere climate and forecasts in the ECMWF model through a nonorographic gravity wave drag parameterization, J. Climate, 23, 5905-5926, DOI: 10.1175/2010JCLI3490.1.

Ortland, D. A., and M. J. Alexander (2006), Gravity wave influence on the global structure of the diurnal tide in the mesosphere and lower thermosphere, J. Geophys. Res., 111(A10), A10S10, doi:10.1029/2005JA011467.

Peralta, J., R. Hueso, A. Sánchez-Lavega, G. Piccioni, O. Lanciano, and P. Drossart (2008), Characterization of mesoscale gravity waves in the upper and lower clouds of Venus from VEX-VIRTIS images, J. Geophys. Res. Planets, 113(E12), doi:10.1029/2008JE003185.

Piccioni, G., et al. (2009), Near-IR oxygen nightglow observed by VIRTIS in the Venus upper atmosphere, J. Geophys. Res. Planets, 114, E00B38, doi:10.1029/2008JE003133.

Roldán, C., M. A. López-Valverde, M. López-Puertas, and D. P. Edwards (2000), Non-LTE infrared emissions of $\mathrm{CO}_{2}$ in the atmosphere of Venus, Icarus, 147, 11-25, doi:10.1006/icar.2000.6432.

Rossow, W. B., S. B. Fels, and P. H. Stone (1980), Comments on "A threedimensional model of dynamical processes in the Venus atmosphere", J. Atmos. Sci., 37, 250-252, doi:10.1175/1520-0469(1980)037<0250: COTDMO $>2.0 . \mathrm{CO} ; 2$.

Sato, K., S. Tateno, S. Watanabe, and Y. Kawatani (2012), Gravity wave characteristics in the southern hemisphere revealed by a high-resolution middle-atmosphere general circulation model, J. Atmos. Sci., 69, 1378-1396 (doi: http://dx.doi.org/10.1175/JAS-D-11-0101.1)

Schofield, J. T., and F. W. Taylor (1983), Measurements of the mean, solarfixed temperature and cloud structure of the middle atmosphere of Venus, Quart. J. Roy. Meteor. Soc., 109, 57-80, doi:10.1256/smsqj.45903.

Schubert, G. (1983), General circulation and the dynamical state of the Venus atmosphere, in Venus, edited by D. M. Hunten, L. Colin, T. M. Donahue, \& V. I. Moroz, pp. 681-765. 


\section{ZALUCHA ET AL.: GRAVITY WAVES IN A VENUS MODEL}

Scinocca, J. (2002), The effect of back-reflection in the parameterization of nonorographic gravity-wave drag, J. Meteorol. Soc. Japan, 80(4B), 939-962.

Seiff, A. (1991), Waves in Venus's middle and upper atmosphere: Implications of Pioneer Venus probe data above the clouds, J. Geophys. Res., 96, 11,021-11,032, doi:10.1029/91JA01101.

Seiff, A., D. B. Kirk, R. E. Young, R. C. Blanchard, J. T. Findlay, G. M. Kelly, and S. C. Sommer (1980), Measurements of thermal structure and thermal contrasts in the atmosphere of Venus and related dynamical observations-Results from the four Pioneer Venus probes, J. Geophys. Res., 85, 7903-7933, doi:10.1029/JA085iA13p07903.

Shepherd, T. G., K. Semeniuk, and J. N. Koshyk (1996), Sponge layer feedbacks in middle-atmosphere models, J. Geophys. Res., 101, 23,447-23,464, doi:10.1029/96JD01994.

Soret, L., J.-C. Gérard, F. Montmessin, G. Piccioni, P. Drossart, and J.-L. Bertaux (2012), Atomic oxygen on the Venus nightside: Global distribution deduced from airglow mapping, Icarus, 217(2), 849 - 855, doi:10.1016/j. icarus.2011.03.034.

Taylor, F. W., et al. (1980), Structure and meteorology of the middle atmosphere of Venus infrared remote sensing from the Pioneer orbiter, J. Geophys. Res., 85, 7963-8006, doi:10.1029/JA085iA13p07963. von Zahn, U., K. H. Fricke, H. Hoffmann, and K. Pelka (1979), VenusEddy coefficients in the thermosphere and the inferred helium content of the lower atmosphere, Geophys. Res. Lett., 6, 337-340.

von Zahn, U., K. H. Fricke, D. M. Hunten, D. Krankowsky, K. Mauersberger, and O. A. Nier (1980), The upper atmosphere of Venus during morning conditions, J. Geophys. Res., 85, 7829-7840, doi:10.1029/ JA085iA13p07829.

Warner, C., and M. McIntyre (2001), An ultra-simple spectral parameterization for non-orographic gravity waves, J. Atmos. Sci., 58, 1837-1857.

Yiğit, E., A. D. Aylward, and A. S. Medvedev (2008), Parameterization of the effects of vertically propagating gravity waves for thermosphere general circulation models: Sensitivity study, J. Geophys. Res. - Atmos., 113(D12), 19,106, doi:10.1029/2008JD010135.

Yiğit, E., A. S. Medvedev, A. D. Aylward, P. Hartogh, and M. J. Harris (2009), Modeling the effects of gravity wave momentum deposition on the general circulation above the turbopause, J. Geophys. Res. - Atmos., 114(D13), D07101, doi:10.1029/2008JD011132.

Zhang, S., S. W. Bougher, and M. J. Alexander (1996), The impact of gravity waves on the Venus thermosphere and $\mathrm{O}_{2}$ IR nightglow, J. Geophys. Res., 1012, 23,195-23,206, doi:10.1029/96JE02035. 